\title{
5-FU induced cardiotoxicity: case series and review of the literature
}

\author{
Cai Yuan ${ }^{1 *}$ D, Hiral Parekh ${ }^{1}$, Carmen Allegra' ${ }^{1}$, Thomas J. George ${ }^{1}$ and Jason S. Starr ${ }^{2}$
}

\begin{abstract}
Background: 5-Fluorouracil (5-FU) is an antimetabolite chemotherapy used for a variety of solid tumors. It has the potential to cause a wide spectrum of cardiotoxicity, ranging from asymptomatic electrocardiographic changes to cardiomyopathy and subsequent cardiac failure. Main body of the abstract: We present two descriptive cases of new-onset severe cardiomyopathy induced by 5-FU followed by a review of the literature.
\end{abstract}

Conclusion: Our case series emphasizes the importance of early recognition of this rare complication and prompt cessation of 5-FU, as cardiac dysfunction in this context is potentially reversible.

Keywords: Fluoropyrimidine, 5-FU, 5-fluorouracil, Cardiotoxicity, Cancer, Colorectal cancer, Antimetabolite, Toxicity, Cancer complications

\section{Background}

5-fluorouracil (5-FU) is a fluoropyrimidine (FP) antimetabolite agent used in a variety of solid tumors treatment. A potential severe side effect of 5-FU is cardiotoxicity, which often presents with chest pain related to coronary vasospasm. More serious cardiotoxicity, including dilated cardiomyopathy, ventricular arrhythmia, and sudden cardiac death has also been reported in the literature [1-4]. 5FU cardiotoxicity is only second to anthracyclines in terms of incidence of cardiotoxicity [5, 6]. Further, cardiotoxicity induced by 5 -FU carries a high risk of morbidity and mortality if left unrecognized [7].

\section{Main text \\ Case presentations \\ Case 1}

A 47-year-old woman with no known history, or risk factors, of cardiac disease, was diagnosed with stage III colon adenocarcinoma. After undergoing laparoscopic ileocolectomy, the patient was started on adjuvant chemotherapy with modified FOLFOX6 (fluorouracil, leucovorin, and oxaliplatin). 5-FU was given as bolus at $400 \mathrm{mg} / \mathrm{m} 2$, followed by $1200 \mathrm{mg} / \mathrm{m} 2 /$ day continuous infusion over $46 \mathrm{~h}$. Approximately $12 \mathrm{~h}$ into receiving the

\footnotetext{
* Correspondence: Caiyuan88@gmail.com

${ }^{1}$ Division of Hematology \& Oncology, Department of Medicine, University of Florida, 8962 SW 73rd Lane, Gainesville, FL 32608, USA

Full list of author information is available at the end of the article
}

first infusional dose of 5-FU, the patient developed progressive substernal chest pain and shortness of breath. Electrocardiography (ECG) revealed hyperacute $\mathrm{T}$ waves with no ST elevation or depression (Fig. 1a). Initially, cardiac biomarkers indicated a mildly elevated troponin I at the level of $0.05 \mathrm{ng} / \mathrm{ml}$ (normal range $<0.04 \mathrm{ng} / \mathrm{ml}$ ), with a peak level of $0.14 \mathrm{ng} / \mathrm{ml}$ at $48 \mathrm{~h}$. Echocardiogram on the following day revealed severely reduced left ventricular function with an ejection fraction (EF) of 20 $25 \%$ with severe hypokinesis of the entire left wall. One month earlier the patient had an unremarkable echocardiogram. Subsequent coronary CT revealed normal coronaries with no stenosis. A diagnosis of 5-FU induced cardiomyopathy was made. 5-FU was subsequently discontinued. The patient was seen by a cardio-oncologist and was placed on a beta blocker and ACE inhibitor. Repeat echocardiogram six weeks later revealed normalization of left ventricular function with an EF of $55-60 \%$. The patient was subsequently given one cycle of capecitabine, which she tolerated. However, she was then admitted to hospital multiple times due to other reasons. A decision was made no further chemo should be given since the patient was 12 weeks from surgery.

\section{Case 2}

A 58-year-old woman was diagnosed with stage IV colon adenocarcinoma with metastases. The patient had no history, or risk factors, of cardiac disease. After palliative 


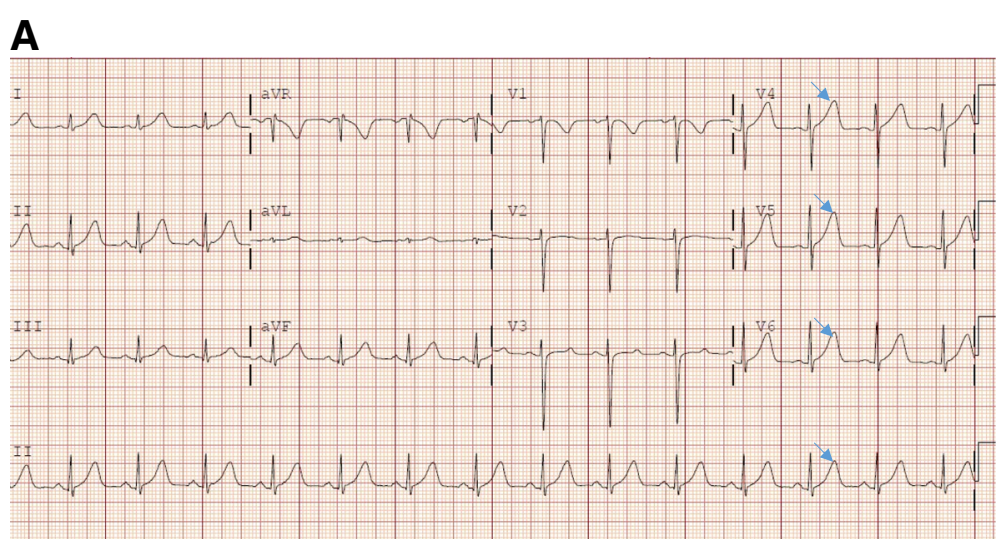

B

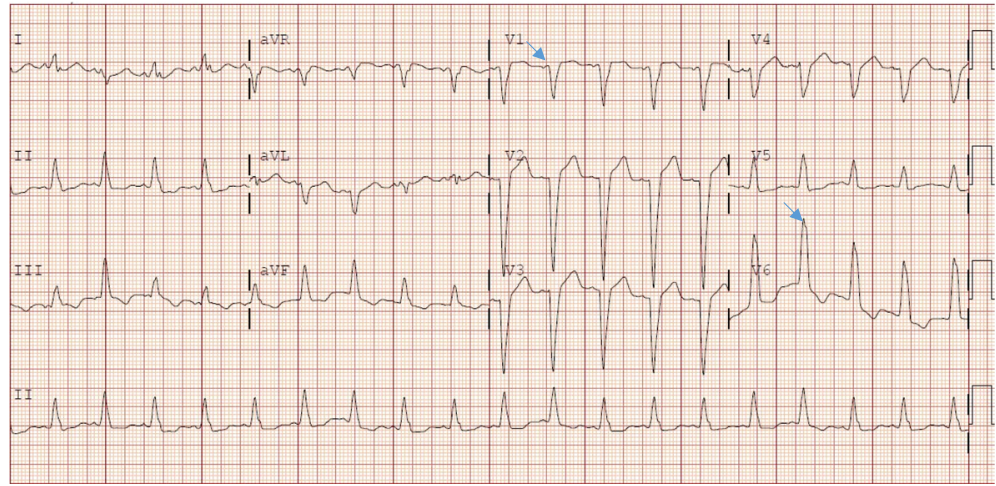

Fig. 1 a 12 lead ECG from Case 1 showing hyperacute T waves (arrows) with no ST elevation or depression. b: 12 lead ECG from case 2 showing sinus tachycardia and a new left bundle branch block (arrows)

laparoscopic end loop colostomy, the patient was started on palliative chemotherapy with modified FOLFOX6. 5$\mathrm{FU}$ was given as bolus at $400 \mathrm{mg} / \mathrm{m} 2$, followed by 1200 $\mathrm{mg} / \mathrm{m} 2 /$ day continuous infusion over $46 \mathrm{~h}$. After 3 cycles of treatments, she presented to the emergency department with severe dyspnea and cough. ECG revealed tachycardia and a new left bundle branch block (Fig. 1b). The cardiac biomarker troponin I was negative. Echocardiogram showed severe decreased left ventricular with an ejection fraction of $20-25 \%$ with severe global hypokinesis. No previous echocardiogram was available for comparison. It was determined based on the acute onset of symptoms and the lack of previous cardiac symptoms that the patient developed 5-FU induced cardiomyopathy. 5-FU was subsequently discontinued. The patient was evaluated by a cardio-oncologist and placed on a beta blocker and ACE inhibitor. A repeat echocardiogram seven months later, unfortunately, showed persistent severe left ventricular dysfunction with an EF 15-20\%. Continued treatment for the cancer included IROX (irinotecan and oxaliplatin) to avoid further 5-FU exposure.

\section{Discussion}

5-FU is a fluoropyrimidine antimetabolite agent used broadly in the treatment of a variety of solid tumors. The more common side effects of 5-FU include diarrhea, mucositis, and myelosuppression. Cardiotoxicity is a more serious side effect ranging from asymptomatic ECG changes to life-threatening cardiogenic shock $[3,4,8]$.

\section{Epidemiology and risk factors (Table 1)}

The reported incidence of cardiotoxicity ranges from 1 to $18 \%$ of patients exposed to fluoropyrimidine [9-15]. Such wide variation could be a reflection of different risk profiles in the study population and also the different administration schedules. The risk of cardiotoxicity is reported to be increased in patients with concurrent chest wall radiation therapy [16], multi-agent chemotherapy [12], and pre-existing cardiac disease (i.e., coronary artery disease $[C A D]$, structural heart disease, and cardiomyopathy) $[9,10,17]$. However, known risk factors for ischemic heart disease such as smoking, diabetes mellitus, obesity, hypertension, and hyperlipidemia do not appear to be associated with the development of cardiotoxicity $[1,11,12,18]$. 
Table 1 Incidence of Cardiotoxicity According to Regimen of Fluoropyrimidine

\begin{tabular}{|c|c|c|c|c|c|}
\hline Author & Cancer Studied & $\begin{array}{l}\text { 5-FU regimen } \\
\text { used }\end{array}$ & $\begin{array}{l}\text { Number of } \\
\text { patients }\end{array}$ & $\begin{array}{l}\text { Overall 5-FU induced cardiotoxicity } \\
\text { incidence }(N)\end{array}$ & Signs and symptoms \\
\hline Polk et al. & Breast cancer & Capecitabine $^{a}$ & 452 & $4.9 \%(22)$ & Chest pain, dyspnea \\
\hline $\begin{array}{l}\text { Jensen et } \\
\text { al. }\end{array}$ & Colorectal cancer & FOLFOX $4^{b}$ & 106 & $8.5 \%(9)$ & Angina \\
\hline $\begin{array}{l}\text { Holubec } \\
\text { et al. }\end{array}$ & Colorectal cancer & $\begin{array}{l}\text { de Gramont } \\
\text { regimenc }^{c} \\
\text { FOLFIRI }^{d}\end{array}$ & 42 & $57 \%(24)$ & Elevated cardiac biomarkers \\
\hline $\begin{array}{l}\text { Yilmaz et } \\
\text { al. }\end{array}$ & Gl cancer & de Gramont ${ }^{c}$ & 27 & $7.4 \%(2)$ & Angina \\
\hline $\begin{array}{l}\text { Turan et } \\
\text { al. }\end{array}$ & Not specified & Not specified & 32 & $12.5 \%(4)$ & Angina, ECG changes \\
\hline $\mathrm{Ng}$ et al. & Colorectal cancer & XELOXe & 153 & $6.5 \%(10)$ & $\begin{array}{l}\text { Angina, Heart failure, Sudden } \\
\text { cardiac death }\end{array}$ \\
\hline $\begin{array}{l}\text { Meydan } \\
\text { et al. }\end{array}$ & $\begin{array}{l}\text { Gl, Breast, and Head and } \\
\text { Neck cancers }\end{array}$ & $\begin{array}{l}\text { de Gramont } \\
\text { regimenc }\end{array}$ & 231 & $3.9 \%(9)$ & $\begin{array}{l}\text { Acute coronary syndrome, } \\
\text { heart failure, cardiac arrhythmia }\end{array}$ \\
\hline
\end{tabular}

${ }^{\mathrm{a} C a p e c i t a b i n e: ~} 1000 \mathrm{mg} / \mathrm{m}^{2}$ orally twice daily

${ }^{b}$ FOLFOX4: oxaliplatin $85 \mathrm{mg} / \mathrm{m}^{2}$ IV, leucovorin $200 \mathrm{mg} / \mathrm{m}^{2} \mathrm{IV}, 5-\mathrm{FU}$ IV bolus $400 \mathrm{mg} / \mathrm{m}^{2}$ followed by continuous IV infusion 5 -FU $600 \mathrm{mg} / \mathrm{m}^{2}$ over $22 \mathrm{~h}$ 'de Gramont regimen: leucovorin $200 \mathrm{mg} / \mathrm{m}^{2} \mathrm{IV}, 5-\mathrm{FU}$ bolus $400 \mathrm{mg} / \mathrm{m}^{2}$ and $5-\mathrm{FU} 600 \mathrm{mg} / \mathrm{m}^{2}$ continuous IV infusion over $22 \mathrm{~h}$

${ }^{d}$ FOLFIRI: irinotecan $180 \mathrm{mg} / \mathrm{m}^{2}$ IV, leucovorin $400 \mathrm{mg} / \mathrm{m}^{2} \mathrm{IV}, 5-\mathrm{FU}$ IV bolus $400 \mathrm{mg} / \mathrm{m}^{2}$ followed by 5 -FU $2400 \mathrm{mg} / \mathrm{m}^{2}$ continuous IV infusion over $46 \mathrm{~h}$

eXELOX: capecitabine $1000 \mathrm{mg} / \mathrm{m}^{2}$ two times per day on day $1-14$, oxaliplatin $130 \mathrm{mg} / \mathrm{m}^{2} \mathrm{IV}$ on day 1

Protracted infusion of 5-FU is a well-recognized risk factor for patients to develop cardiotoxicity $[8,11,19-21]$. A review of 377 cases of 5-FU related cardiotoxicity confirmed that the majority of cases of cardiotoxicity occur in the setting of continuous infusion [3]. In a retrospective study comparing different chemotherapy regimens with 5-FU used to treat colorectal and gastric cancer, patients receiving continuous infusion 5-FU therapy had a reported incidence of cardiotoxicity as high as $10-18 \%$. This is in contrast to a $5 \%$ rate of cardiotoxicity in patients receiving 5-FU in a bolus fashion [8]. In another study evaluating 1000 patients receiving $5-\mathrm{FU}$, the rates of cardiotoxicity were similarly lower $(1.6-3 \%)$ with bolus administration of 5-FU [9]. The likely reason for differences in cardiotoxicity with continuous versus bolus infusion is that the half-life of 5 -FU is $15-20 \mathrm{~min}$ and thus the drug is rapidly cleared when given in bolus fashion [22].

Alternatively, capecitabine, an orally available 5-FU prodrug, was found to have an incidence of cardiotoxicity of $3-9 \%$, which is similar to that of continuous 5 -FU infusion therapy $[11,18,22]$. TAS-102 (Lonsurf) is an oral cytotoxic drug that has a nucleoside analog (trifluridine) and a thymidine phosphorylase inhibitor (tipiracil) approved for use in refractory metastatic colorectal cancer. In the registration phase III study that led to its FDA approval, only one patient treated with TAS-102 was reported to have an episode of cardiac ischemia (unknown mechanism and attribution) among 800 treated patients [23]. In a recent review, Petrelli et al. suggest that TAS-102 could represent an alternative option for patients with increased risk factors of developing cardiac events [24]. S-1 is a drug that contains fluorouracil prodrug tefagur and gimeracil used in gastric cancer. In the published phase II or III studies of
S-1, no grade III or IV cardiovascular events were reported [25-27]. S-1 currently is not available in the USA.

It is also important to point out that asymptomatic ECG changes have been reported to be as high as $88 \%$ [17]. 5-FU chemotherapy is commonly administered in the outpatient setting, and patients do not require routine cardiac monitoring. Thus, subclinical ECG changes and asymptomatic myocardial injury are likely an underreported phenomenon.

\section{Clinical manifestations (Table 2)}

Angina is the most common manifestations of fluoropyrimidine-induced cardiotoxicity, which can occur in up to $19-45 \%$ of patients with or without ST and T wave ECG changes [3, 28]. Wacker et al. reported in a case series that up to $19 \%$ of the patients experienced angina during treatment, with episodes lasting up to $12 \mathrm{~h}$ after cessation of drug infusion [28].

Less commonly, myocardial infarction, congestive heart failure, and reversible cardiomyopathy have been reported [1, 29-31]. In one report, the incidence of cardiomyopathy with left ventricular dysfunction was estimated to be $2 \%$

Table 2 Potential Clinical and ECG Manifestations of Fluoropyrimidine Induced Cardiotoxicity

\begin{tabular}{ll}
\hline Clinical & ECG \\
\hline Myocardial infarction & Supraventricular tachycardia \\
Cardiomyopathy & Ventricular tachycardia \\
Myocarditis & QT prolongation \\
Pericarditis & Ischemic changes (i.e., ST and \\
Coronary dissection & T wave abnormalities) \\
Sudden cardiac death & \\
\hline
\end{tabular}


[3]. Severe cardiotoxic manifestations have been reported in case reports, including coronary dissection, ventricular tachyarrhythmia, cardiogenic shock (requiring intra-aortic balloon pump and extracorporeal membrane oxygenation support), and sudden cardiac death [32-34].

Aside from symptomatic cardiotoxicity, some patients may develop silent cardiac ischemia. In a prospective study, Rezkalla et al. identified an association between ischemic ECG changes and 5-FU infusion in otherwise asymptomatic patients who underwent ambulatory rhythm monitoring [17]. Other arrhythmias including QT prolongations, and less commonly torsades de pointes have been reported $[17,28,35]$.

\section{Mechanisms of cardiotoxicity (Table 3)}

The precise mechanism of cardiotoxicity from fluoropyrimidines remains unclear, but several mechanisms have been proposed, including coronary artery vasospasm, direct toxicity to the myocardium, endothelial dysfunction, and a hypercoagulable state causing thrombosis. It should be noted that these mechanisms were elucidated through animal modeling, case reports, and small clinical studies.

\section{Coronary vasospasm}

Coronary vasospasm leading to an acute ischemic event is probably the most well recognized cardiac side effect of fluoropyrimidines. Patients present with signs and symptoms of acute coronary syndrome and ECG often reveals ST segment changes along with a rise in cardiac biomarkers, such as troponin. However, coronary angiography is typically normal without evidence of a thrombotic event [36]. Mosseri et al. found that protein kinase $\mathrm{C}$ may be a mediator of 5-FU-induced vasoconstriction, and demonstrated endothelium-independent vasoconstriction of rabbit aortic rings with increasing doses of 5-FU [37]. Additionally, Thyss et al. described high plasma levels of endothelin-1 in patients that experienced 5-FU-induced cardiotoxicity [38]. Endothelin-1 is a potent vasoconstrictor that has a known regulatory role in vascular vasomotor tone in coronary artery disease $[39,40]$. The efficacy of vasodilator therapy including non-dihydropyridine calcium channel blockers such as verapamil and nitrates were noted to be effective in resolving chest pain and dynamic ECG changes in the setting of 5-FU induced cardiotoxicity [41, 42]. These data support that theory of coronary vasoconstriction as part of the pathophysiology of fluoropyrimidine-induced cardiotoxicity. As noted earlier in this manuscript coronary vasospasm is seen with continuous infusion of 5-FU, or alternatively with the fluoropyrimidine, capecitabine.

\section{Direct myocardial injury}

Another possible mechanism of cardiotoxicity is a direct toxic effect of fluoropyrimidine on cardiomyocytes, as evidenced by global systolic dysfunction, which does not correspond to any individual coronary artery territory [10]. An animal study of rabbits demonstrated 5-FU induced diffuse myocarditis with necrosis [43]. Sarcoplasmic reticulum dilatation was demonstrated on one case report utilizing ventricular biopsy, which is similar to the mechanism of doxorubicin-associated cardiomyopathy [44]. One of the down-stream degradation compounds of 5-FU is alpha-fluoro-beta-alanine (FBAL), which appears to serve as an important mediator of the direct toxic effect $[45,46]$. In a case report, Muneoka et al. demonstrated elevated levels of FBAL in a patient after 5-FU induced myocardial infarction. The patient was then treated with the prodrug S-1, an oral fluoropyrimidine that does not metabolize to FBAL, without recurrent cardiac adverse effects [46].

\section{Vascular Endothelial Dysfunction \& Impaired Oxygen Delivery}

Vascular dysfunction with microthrombi formation has been shown to be a potential mechanism that results in fluoropyrimidine-induced cardiotoxicity. The microthrombotic occlusion is usually not detectable by coronary angiography [45]. Several animal studies examined the direct toxic effects of 5-FU on vascular endothelial cells and noted direct endothelial damage and subsequent platelet and fibrin accumulation, which was confirmed by electron microscopy [47, 48]. Experimental studies also suggest that the use of anticoagulation therapy may partially mitigate this toxicity [2, 49]. Some authors, on the other hand, believe free oxygen radicals also play a role in cytotoxic endothelial dysfunction [50].

Spasojevic et al. demonstrated that 5-FU causes changes to the erythrocyte membranes leading to increased fluidity and conversion of the erythrocyte from its usual biconcave shape to an echinocyte shape $[51,52]$. The resulted membrane changes diminish the erythrocyte's ability to deliver and transport oxygen, resulting in myocardial ischemia and injury.

Table 3 Proposed Mechanisms of Fluoropyrimidine Induced Cardiotoxicity

\begin{tabular}{llll}
\hline $\begin{array}{l}\text { Coronary } \\
\text { Vasospasm }\end{array}$ & Direct Myocardial Injury & Vascular Endothelial Dysfunction & Impaired Oxygen Delivery \\
\hline - Protein kinase C & • Alpha-fluoro-beta-alanine & $\bullet$ Microthrombotic occlusions resulting from direct & $\bullet$ Erythrocyte membranes change leading \\
- Endothelin-I & (FBAL) & toxic effect of 5-FU on vascular endothelial cells & to diminished ability to deliver oxygen \\
& (breakdown product of 5-FU) & $\bullet$ Oxygen free radicals & \\
\hline
\end{tabular}




\section{Treatment}

There is no standard treatment recommendation for fluoropyrimidine induced cardiotoxicity. The current consensus is that 5-FU should be discontinued as soon as potential cardiotoxicity is suspected. Upon fluoropyrimidine discontinuation, the patient should be treated symptomatically with antianginal therapy such as nitrates and non-dihydropyridine calcium channel blocker as empiric treatment for acute coronary vasospasm. It is reported that this approach has been shown to abort symptoms in up to approximately $70 \%$ of patients $[3,8]$.

Multidisciplinary discussion between oncology and cardiology is critical in managing cancer patients with suspected 5-FU associated cardiotoxicity. Ensuring that symptoms have completely resolved before attempting further chemotherapy. These patients should be managed with risk stratification and treatment per ACC/AHA guidelines. As preexisting CAD is a known risk factor for cardiotoxicity, risk reduction strategies with smoking secession, optimizing blood pressure, statin use and aggressive diabetes control should be implemented [45].

In 2015, uridine triacetate was approved by the Food and Drug Administration (FDA) as an antidote to 5-FU (or capecitabine) overdose or for those who exhibit early-onset, severe or life-threatening toxicity affecting the cardiac or central nervous system, and/or early onset, unusually severe adverse reactions (e.g. gastrointestinal toxicity and/or neutropenia) [53]. Uridine triacetate is an oral active prodrug of uridine, which is a naturally occurring nucleotide and competes with the 5-FU metabolite, for incorporation into RNA of normal tissue. It was shown in a small study that it has superior survival rate in treated patients who experienced life-threatening toxicity from 5-FU when compared to supportive care only in a historical case cohort [54]. However, due to the limitation of the study, further studies are needed to clarify its role of in the treatment of fluoropyrimidine associated cardiotoxicity.

In some reports, the cardiotoxicity appears to be reversible after cessation of therapy as demonstrated by our first case. This is especially true in patients without underlying cardiac disease and when vasospasm alone induces a hibernating myocardium that recovers with adequate time and reperfusion [5]. Thus, high clinical awareness of this problem is critical, as early cessation of therapy may prevent further damage and allow for potential reversal of damage. Referral to a cardiac specialist, ideally a cardio-oncologist, is prudent for medical optimization and vigilant monitoring.

\section{Prophylaxis and prevention}

Several pharmacological interventions have been assessed as preventive strategies with mixed results. A study done by Eskilsson et al. pursued prophylactic administration of verapamil, a non-dihydropyridine calcium channel blocker, to prevent 5-FU induced vasospasm. The study did not show a benefit for verapamil in this capacity [55]. On the other hand, Ambrosy et al. reported that five patients who previously experienced chest pain and dyspnea with their initial doses of capecitabine had resolution of any further symptoms with co-administration of diltiazem [56]. Nifedipine was also found in a case report as an effective agent to prevent 5-FU induced coronary vasospasm when the patient was receiving continuous 5-FU infusion for gastric cancer [57]. Nitrates have also been tried with variable success [58, 59]. There is currently no randomized trial evaluating the role of calcium channel blocker or nitrates in this setting. These agents could be used in selected situations on a case by case basis.

Patients re-challenged with 5-FU therapy after the initial insult have a risk of recurrence of cardiotoxicity reported to be as high as 82 to $100 \%$ [60], and death can be up to $13 \%[3,10]$. Important considerations before restarting chemotherapy are if the agent in question provides the best chances for survival with cancer treatment and if there is an alternative chemo regimen that can be used. As mentioned above, TAS-102 may be an alternative option for patients with increased risk factors of developing cardiac events with colorectal cancer [24].

Fluoropyrimidine reintroduction can be considered if it is deemed the most efficacious choice per multidisciplinary discussion and patients are well informed about the benefits and risks of resuming therapy. There is limited evidence supporting switching to 5-FU bolus in patients who experienced cardiotoxicity with infusional 5 -FU or capecitabine $[58,61,62]$. Jensen et al. reported significantly decreased cardiotoxicity in 9 out of 12 patients receiving prophylaxis with either a beta-blocker, calcium channel blocker, or long-acting nitrate as well as dose-reduced fluoropyrimidine [8]. Outpatient ECGs monitoring may be important to implement in patients with reintroduced therapy to detect silent ischemia and arrhythmia [17, 63].

\section{Conclusion}

Cardiotoxicity induced by fluoropyrimidines is a clinically relevant side effect that all oncologists should be familiar with, as early recognition is crucial to prevent significant morbidity. The mechanisms for cardiotoxicity include coronary vasospasm, direct myocardial injury, vascular endothelial dysfunction, and impaired oxygen delivery. There is currently no consensus on the optimal treatment and/or prophylaxis of these complications, aside from early detection and cessation of the offending agent. Vigilant monitoring for cardiotoxicity with early cessation and supportive care intervention remains the most effective treatment with some opportunity for cardiac recovery. 


\section{Abbreviations}

5-FU: 5-Fluorouracil; ACC: American college of cardiology; ACE inhibitors: Angiotensin-converting enzyme inhibitors; AHA: American heart association; CAD: Coronary heart disease; CT: Computerized tomography; ECG: Electrocardiography; EF: Ejection fraction; FBAL: Alpha-fluoro-betaalanine; FDA: Food and Drug Administration; FOLFOX6: fluorouracil, leucovorin, and oxaliplatin; FP: fluoropyrimidine; IROX: Irinotecan and oxaliplatin; TAS 102: Trifluridine and tipiracil

\section{Acknowledgements}

Not applicable

\section{Authors' contributions}

(I) Conception and design: HP, JSSt; (II) Administrative support: None; (III) Provision of study materials or patients: HP, JSS; (IV) Collection and assembly of data: CY, HP, JSS; (V) Data analysis and interpretation: CY, HP, JSS; (VI) Manuscript writing: All authors; (VII) Final approval of manuscript: All authors.

\section{Funding}

Not applicable

\section{Availability of data and materials}

Not applicable

\section{Ethics approval and consent to participate}

Not applicable

\section{Consent for publication}

Obtained

\section{Competing interests}

The authors declare that they have no competing interests.

\section{Author details}

${ }^{1}$ Division of Hematology \& Oncology, Department of Medicine, University of Florida, 8962 SW 73rd Lane, Gainesville, FL 32608, USA. Division of Hematology \& Oncology, Mayo Clinic, Jacksonville, FL, USA.

Received: 6 June 2019 Accepted: 31 July 2019

Published online: 06 September 2019

\section{References}

1. Polk A, Vaage-Nilsen M, Vistisen K, Nielsen DL. Cardiotoxicity in cancer patients treated with 5-fluorouracil or capecitabine: a systematic review of incidence, manifestations and predisposing factors. Cancer Treat Rev. 2013; 39(8):974-84.

2. Jensen SA, Sorensen JB. 5-fluorouracil-based therapy induces endovascular injury having potential significance to development of clinically overt cardiotoxicity. Cancer Chemother Pharmacol. 2012;69(1):57-64.

3. Saif MW, Shah MM, Shah AR. Fluoropyrimidine-associated cardiotoxicity: revisited. Expert Opin Drug Saf. 2009;8(2):191-202.

4. Stewart T, Pavlakis N, Ward M. Cardiotoxicity with 5-fluorouracil and capecitabine: more than just vasospastic angina. Intern Med J. 2010;40(4):303-7.

5. Akhtar SS, Salim KP, Bano ZA. Symptomatic cardiotoxicity with high-dose 5fluorouracil infusion: a prospective study. Oncology. 1993;50(6):441-4.

6. Anand AJ. Fluorouracil cardiotoxicity. Ann Pharmacother. 1994;28(3):374-8.

7. Khawaja MZ, Cafferkey C, Rajani R, Redwood S, Cunningham D. Cardiac complications and manifestations of chemotherapy for cancer. Heart. 2014 100(14): $1133-40$

8. Jensen SA, Sorensen JB. Risk factors and prevention of cardiotoxicity induced by 5-fluorouracil or capecitabine. Cancer Chemother Pharmacol. 2006:58(4):487-93.

9. Labianca R, Beretta G, Clerici M, Fraschini P, Luporini G. Cardiac toxicity of 5fluorouracil: a study on 1083 patients. Tumori. 1982;68(6):505-10.

10. de Forni M, Malet-Martino MC, Jaillais P, Shubinski RE, Bachaud JM, Lemaire $L$, et al. Cardiotoxicity of high-dose continuous infusion fluorouracil: a prospective clinical study. J Clin Oncol. 1992:10(11):1795-801.

11. Kosmas C, Kallistratos MS, Kopterides P, Syrios J, Skopelitis H, Mylonakis N, et al. Cardiotoxicity of fluoropyrimidines in different schedules of administration: a prospective study. J Cancer Res Clin Oncol. 2008;134(1):75-82.
12. Meyer CC, Calis KA, Burke LB, Walawander CA, Grasela TH. Symptomatic cardiotoxicity associated with 5-fluorouracil. Pharmacotherapy. 1997:17(4):729-36.

13. Holubec L Jr, Topolcan O, Finek J, Salvet J, Svoboda T, Svobodova S, et al. Dynamic monitoring of cardio-specific markers and markers of thyroid gland function in cancer patients--a pilot study. Anticancer Res. 2007;27(4A):1883-6.

14. Yilmaz U, Oztop I, Ciloglu A, Okan T, Tekin U, Yaren A, et al. 5-fluorouracil increases the number and complexity of premature complexes in the heart: a prospective study using ambulatory ECG monitoring. Int J Clin Pract. 2007; 61(5):795-801.

15. Turan T, Agac MT, Aykan AC, Kul S, Akyuz AR, Gokdeniz T, et al. Usefulness of heart-type fatty acid-binding protein and myocardial performance index for early detection of 5-fluorouracil cardiotoxicity. Angiology. 2017;68(1):52-8.

16. Bovelli D, Plataniotis G, Roila F, Group EGW. Cardiotoxicity of chemotherapeutic agents and radiotherapy-related heart disease: ESMO clinical practice guidelines. Ann Oncol. 2010;21(Suppl 5):v277-82.

17. Rezkalla S, Kloner RA, Ensley J, al-Sarraf M, Revels S, Olivenstein A, et al. Continuous ambulatory ECG monitoring during fluorouracil therapy: a prospective study. J Clin Oncol. 1989;7(4):509-14.

18. Ng M, Cunningham D, Norman AR. The frequency and pattern of cardiotoxicity observed with capecitabine used in conjunction with oxaliplatin in patients treated for advanced colorectal cancer (CRC). Eur J Cancer. 2005;41(11):1542-6.

19. Khan MA, Masood N, Husain N, Ahmad B, Aziz T, Naeem A. A retrospective study of cardiotoxicities induced by 5-fluouracil (5-FU) and 5-FU based chemotherapy regimens in Pakistani adult cancer patients at Shaukat Khanum memorial Cancer hospital \& research center. J Pak Med Assoc. 2012;62(5):430-4.

20. Meydan N, Kundak I, Yavuzsen T, Oztop I, Barutca S, Yilmaz U, et al. Cardiotoxicity of de Gramont's regimen: incidence, clinical characteristics and long-term follow-up. Jpn J Clin Oncol. 2005:35(5):265-70.

21. Sorrentino MF, Kim J, Foderaro AE, Truesdell AG. 5-fluorouracil induced cardiotoxicity: review of the literature. Cardiol J. 2012;19(5):453-8.

22. Sara JD, Kaur J, Khodadadi R, Rehman M, Lobo R, Chakrabarti S, et al. 5fluorouracil and cardiotoxicity: a review. Ther Adv Med Oncol. 2018:10: 1758835918780140 .

23. Longo-Munoz F, Argiles G, Tabernero J, Cervantes A, Gravalos C, Pericay C, et al. Efficacy of trifluridine and tipiracil (TAS-102) versus placebo, with supportive care, in a randomized, controlled trial of patients with metastatic colorectal cancer from Spain: results of a subgroup analysis of the phase 3 RECOURSE trial. Clin Transl Oncol. 2017;19(2):227-35.

24. Petrelli F, Barni S, Bertocchi P, Zaniboni A. TAS-102, the first "cardio-gentle" fluoropyrimidine in the colorectal cancer landscape? BMC Cancer. 2016:16:386.

25. Vaflard P, Ederhy S, Torregrosa C, Andre T, Cohen R, Lopez-Trabada D. Fluoropyrimidines cardiac toxicity: 5-fluorouracil, capecitabine, compound S1 and trifluridine/tipiracil. Bull Cancer. 2018;105(7-8):707-19.

26. Nagashima F, Ohtsu A, Yoshida S, Ito K. Japanese nationwide postmarketing survey of S-1 in patients with advanced gastric cancer. Gastric Cancer. 2005;8(1):6-11

27. Lee JL, Kang YK, Kang HJ, Lee KH, Zang DY, Ryoo BY, et al. A randomised multicentre phase II trial of capecitabine vs S-1 as first-line treatment in elderly patients with metastatic or recurrent unresectable gastric cancer. $\mathrm{Br}$ J Cancer. 2008;99(4):584-90.

28. Wacker A, Lersch C, Scherpinski U, Reindl L, Seyfarth M. High incidence of angina pectoris in patients treated with 5-fluorouracil. A planned surveillance study with 102 patients. Oncology. 2003:65(2):108-12.

29. Robben NC, Pippas AW, Moore JO. The syndrome of 5-fluorouracil cardiotoxicity. An elusive cardiopathy. Cancer. 1993;71(2):493-509.

30. Calik AN, Celiker E, Velibey Y, Cagdas M, Guzelburc O. Initial dose effect of 5fluorouracil: rapidly improving severe, acute toxic myopericarditis. Am J Emerg Med. 2012;30(1):257 e1-3.

31. Dalzell JR, Samuel LM. The spectrum of 5-fluorouracil cardiotoxicity. AntiCancer Drugs. 2009:20(1):79-80

32. Rateesh S, Shekar K, Naidoo R, Mittal D, Bhaskar B. Use of extracorporeal membrane oxygenation for mechanical circulatory support in a patient with 5-fluorouracil induced acute heart failure. Circ Heart Fail. 2015;8(2):381-3.

33. Hollriegel R, Fischer J, Schuler G. Early extracorporeal membrane oxygenation support for 5-fluorouracil-induced acute heart failure with cardiogenic shock. Heart Views. 2014:15(1):26-8.

34. David JS, Gueugniaud PY, Hepp A, Gaussorgues P, Petit P. Severe heart failure secondary to 5-fluorouracil and low-doses of folinic acid: usefulness of an intra-aortic balloon pump. Crit Care Med. 2000;28(10):3558-60. 
35. Polk A, Vistisen K, Vaage-Nilsen M, Nielsen DL. A systematic review of the pathophysiology of 5-fluorouracil-induced cardiotoxicity. BMC Pharmacol Toxicol. 2014;15:47.

36. Shoemaker LK, Arora U, Rocha Lima CM. 5-fluorouracil-induced coronary vasospasm. Cancer Control. 2004;11(1):46-9.

37. Mosseri M, Fingert HJ, Varticovski L, Chokshi S, Isner JM. In vitro evidence that myocardial ischemia resulting from 5-fluorouracil chemotherapy is due to protein kinase C-mediated vasoconstriction of vascular smooth muscle. Cancer Res. 1993;53(13):3028-33.

38.' Thyss A, Gaspard MH, Marsault R, Milano G, Frelin C, Schneider M. Very high endothelin plasma levels in patients with 5-FU cardiotoxicity. Ann Oncol. 1992;3(1):88

39. MacCarthy PA, Pegge NC, Prendergast BD, Shah AM, Groves PH. The physiological role of endogenous endothelin in the regulation of human coronary vasomotor tone. J Am Coll Cardiol. 2001;37(1):137-43.

40. Kinlay S, Behrendt D, Wainstein M, Beltrame J, Fang JC, Creager MA, et al. Role of endothelin-1 in the active constriction of human atherosclerotic coronary arteries. Circulation. 2001;104(10):1114-8.

41. Farina A, Malafronte C, Valsecchi MA, Achilli F. Capecitabine-induced cardiotoxicity: when to suspect? How to manage? A case report. J Cardiovasc Med (Hagerstown). 2009;10(9):722-6.

42. Senturk T, Kanat O, Evrensel T, Aydinlar A. Capecitabine-induced cardiotoxicity mimicking myocardial infarction. Neth Heart J. 2009;17(7-8):277-80.

43. Tsibiribi P, Bui-Xuan C, Bui-Xuan B, Lombard-Bohas C, Duperret S, Belkhiria $M$, et al. Cardiac lesions induced by 5 -fluorouracil in the rabbit. Hum Exp Toxicol. 2006;25(6):305-9.

44. Kuropkat C, Griem K, Clark J, Rodriquez ER, Hutchinson J, Taylor SG. Severe cardiotoxicity during 5-fluorouracil chemotherapy: a case and literature report. Am J Clin Oncol. 1999;22(5):466-70.

45. Layoun ME, Wickramasinghe CD, Peralta MV, Yang EH. Fluoropyrimidineinduced cardiotoxicity: manifestations, mechanisms, and management. Curr Oncol Rep. 2016;18(6):35

46. Muneoka K, Shirai Y, Yokoyama N, Wakai T, Hatakeyama K. 5-fluorouracil cardiotoxicity induced by alpha-fluoro-beta-alanine. Int J Clin Oncol. 2005; 10(6):441-3

47. Cwikiel M, Eskilsson J, Wieslander JB, Stjernquist U, Albertsson M. The appearance of endothelium in small arteries after treatment with 5fluorouracil. An electron microscopic study of late effects in rabbits. Scanning Microsc. 1996;10(3):805-18 discussion 19.

48. Cwikiel M, Eskilsson J, Albertsson M, Stavenow L. The influence of 5fluorouracil and methotrexate on vascular endothelium. An experimental study using endothelial cells in the culture. Ann Oncol. 1996;7(7):731-7.

49. Kinhult S, Albertsson M, Eskilsson J, Cwikiel M. Antithrombotic treatment in protection against thrombogenic effects of 5-fluorouracil on vascular endothelium: a scanning microscopy evaluation. Scanning. 2001;23(1):1-8.

50. Focaccetti C, Bruno A, Magnani E, Bartolini D, Principi E, Dallaglio K, et al. Effects of 5-fluorouracil on morphology, cell cycle, proliferation, apoptosis, autophagy and ROS production in endothelial cells and cardiomyocytes. PLoS One. 2015;10(2):e0115686.

51. Spasojevic I, Maksimovic V, Zakrzewska J, Bacic G. Effects of 5-fluorouracil on erythrocytes in relation to its cardiotoxicity: membrane structure and functioning. J Chem Inf Model. 2005;45(6):1680-5.

52. Spasojevic I, Jelic S, Zakrzewska J, Bacic G. Decreased oxygen transfer capacity of erythrocytes as a cause of 5-fluorouracil related ischemia. Molecules. 2008;14(1):53-67.

53. Ison G, Beaver JA, McGuinn WD Jr, Palmby TR, Dinin J, Charlab R, et al. FDA approval: uridine triacetate for the treatment of patients following fluorouracil or Capecitabine overdose or exhibiting early-onset severe toxicities following Administration of these Drugs. Clin Cancer Res. 2016;22(18):4545-9.

54. Ma WW, Saif MW, El-Rayes BF, Fakih MG, Cartwright TH, Posey JA, et al. Emergency use of uridine triacetate for the prevention and treatment of lifethreatening 5-fluorouracil and capecitabine toxicity. Cancer. 2017;123(2):345-56

55. Eskilsson J, Albertsson M. Failure of preventing 5-fluorouracil cardiotoxicity by prophylactic treatment with verapamil. Acta Oncol. 1990;29(8):1001-3.

56. Ambrosy AP, Kunz PL, Fisher GA, Witteles RM. Capecitabine-induced chest pain relieved by diltiazem. Am J Cardiol. 2012;110(11):1623-6.

57. Oleksowicz L, Bruckner HW. Prophylaxis of 5-fluorouracil-induced coronary vasospasm with calcium channel blockers. Am J Med. 1988;85(5):750-1.

58. Cianci G, Morelli MF, Cannita K, Morese R, Ricevuto E, Di Rocco ZC, et al. Prophylactic options in patients with 5-fluorouracil-associated cardiotoxicity. Br J Cancer. 2003;88(10):1507-9.
59. Akpek G, Hartshorn KL. Failure of oral nitrate and calcium channel blocker therapy to prevent 5-fluorouracil-related myocardial ischemia: a case report. Cancer Chemother Pharmacol. 1999;43(2):157-61.

60. Becker K, Erckenbrecht JF, Haussinger D, Frieling T. Cardiotoxicity of the antiproliferative compound fluorouracil. Drugs. 1999;57(4):475-84.

61. Saif MW, Garcon MC, Rodriguez G, Rodriguez T. Bolus 5-fluorouracil as an alternative in patients with cardiotoxicity associated with infusion 5fluorouracil and capecitabine: a case series. In vivo (Athens, Greece). 2013;27(4):531-4.

62. Shaib W, Lee V, Saif MW. Bolus 5-Fluorouracil as an alternative modality to infusion 5-Fluorouracil in a patient with rectal cancer and capecitabineinduced cardiotoxicity. In vivo (Athens, Greece). 2009;23(5):821-6.

63. Lestuzzi C, Vaccher E, Talamini R, Lleshi A, Meneguzzo N, Viel E, et al. Effort myocardial ischemia during chemotherapy with 5-fluorouracil: an underestimated risk. Ann Oncol. 2014:25(5):1059-64.

\section{Publisher's Note}

Springer Nature remains neutral with regard to jurisdictional claims in published maps and institutional affiliations.

Ready to submit your research? Choose BMC and benefit from:

- fast, convenient online submission

- thorough peer review by experienced researchers in your field

- rapid publication on acceptance

- support for research data, including large and complex data types

- gold Open Access which fosters wider collaboration and increased citations

- maximum visibility for your research: over $100 \mathrm{M}$ website views per year

At $\mathrm{BMC}$, research is always in progress.

Learn more biomedcentral.com/submissions 